\title{
Vibration Characteristics of Kömürhan Highway Bridge Constructed with Balanced Cantilever Method
}

\author{
Alemdar Bayraktar ${ }^{1}$; Ahmet Can Altunişik ${ }^{2}$; Bariş Sevim³ ; Temel Türker ${ }^{4}$; Arman Domaniç5; and \\ Yavuzhan Taş ${ }^{6}$
}

\begin{abstract}
Kömürhan Highway Bridge is a reinforced concrete box girder bridge located on the 51st km of Elazı̆̆-Malatya Highway over the Firat River. Because of the fact that the Kömürhan Bridge is the only bridge in this part of Firat, it has major logistical importance. So, this paper aims to determine dynamic characteristics such as natural frequencies, mode shapes, and damping ratios of the bridge using experimental measurements and finite-element analyses to evaluate current behavior. The experimental measurements are carried out by ambient vibration tests under traffic loads. Due to the expansion joint in the middle of the bridge, special measurement points are selected and experimental test setups are constituted. Vibration data are gathered from the both box girder and bridge deck. Measurement time, frequency span, and effective mode number are determined by considering similar studies and literature. The peak picking method in the frequency domain is used for the output-only modal identification. An analytical modal analysis is performed on the developed two- and three-dimensional finite-element model of the bridge using SAP2000 software to provide the analytical frequencies and mode shapes. At the end of the study, dynamic characteristics of the Elazı ğ and Malatya parts of the bridge obtained from the experimental measurements are compared with each other and transverse effects on the bridge are determined. Also, experimental and analytical dynamic characteristics are compared. Good agreement is found between dynamic characteristics in the all measurement test setups performed on the box girder and bridge deck and analytical modal analyses.
\end{abstract}

DOI: 10.1061/(ASCE)0887-3828(2009)23:2(90)

CE Database subject headings: Vibration; Finite element method; Bridges; Highway; Turkey.

\section{Introduction}

The Kömürhan Bridge is a reinforced concrete box girder bridge located on the $51 \mathrm{st} \mathrm{km}$ of the Elazığ-Malatya Highway over the Firat River. Because the Kömürhan Bridge is the only bridge in this part of Firat, it has major logistical importance. Construction of the bridge started in 1983 and completed in 1986. Before the construction of the Kömürhan Bridge, arrival between Elazı̆g Malatya cities was ensured by various ways. The arrival was ensured by only rafts and skiff until 1910. Later, a timber bridge constructed during the First World War was used to provide arrival between two cities. But the timber bridge was collapsed owing to increase of the water level, so the arrival was ensured by only rafts and skiffs again. For these purposes it was decided that

\footnotetext{
${ }^{1}$ Professor, Dept. of Civil Engineering, Karadeniz Technical Univ., 61080, Trabzon, Turkey. E-mail: alemdar@ktu.edu.tr

${ }^{2}$ Research Assistant, Dept. of Civil Engineering, Karadeniz Technical Univ., 61080, Trabzon, Turkey. E-mail: ahmetcan8284@hotmail.com

${ }^{3}$ Research Assistant, Dept. of Civil Engineering, Karadeniz Technical Univ., 61080, Trabzon, Turkey. E-mail: bsevim18@hotmail.com

${ }^{4}$ Research Assistant, Dept. of Civil Engineering, Karadeniz Technical Univ., 61080, Trabzon, Turkey. E-mail: temelturker@hotmail.com

${ }^{5}$ Civil Engineer, Yüksel Domaniç Engineering Company, 06800, Ankara, Turkey. E-mail: armandomanic@ hotmail.com

${ }^{6}$ Civil Engineer, General Directorate of Highways, Elazı $\breve{g}$, Turkey. E-mail: ytas@kgm.gov.tr

Note. Discussion open until September 1, 2009. Separate discussions must be submitted for individual papers. The manuscript for this paper was submitted for review and possible publication on April 7, 2008; approved on September 15, 2008. This paper is part of the Journal of Performance of Constructed Facilities, Vol. 23, No. 2, April 1, 2009. (CASCE, ISSN 0887-3828/2009/2-90-99/\$25.00.
}

a reinforced concrete bridge must be constructed at Kömürhan Gullet. The bridge construction started in August 1930 and finished in April 1932. The bridge was called the İsmet Pasha Bridge. The bridge, which had an arch type structural system with 109,60 m main span, was the sixth biggest reinforced concrete bridge in the world when it was constructed. This bridge served the region for many years. But it was thought that this bridge remained under the Karakaya dam reservoir water, which is constructed within the context of the Southeast Anatolia Project, so a new bridge at Kömürhan Gullet was required. Thus, Kömürhan Bridge was constructed from 1983 to 1986 . Kömürhan Bridge has a box girder structural system and some special characteristics because it was the first bridge constructed by the balanced cantilever method in Turkey. Some views of Kömürhan Bridge are given in Fig. 1.

Dynamic characteristics such as natural frequencies, mode shapes, and damping ratios are very important for engineering structures to obtain current behavior. Generally these properties are analytically determined using finite-element analyses. But during the analytical studies, material properties, boundary conditions, and section areas accepted in the design can be changed for various reasons, including, worker mistakes during construction, different load cases exposed to the structure over time which are not considered in the design, and reduced resistance of the structures. So, dynamic characteristics of structures need to be determined based on experimental methods. This procedure is called a modal testing.

The modal testing procedures mostly used in the literature are either frequency response function based testing (using shaker or hammer excitation) or ambient vibration survey. In the former, both the input force and output response are measured. In the 

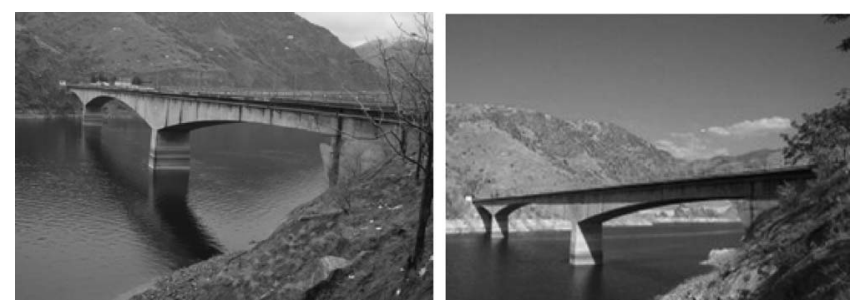

Fig. 1. Some views from the Kömürhan Bridge

latter, only the response is measured and the input force is environmental excitation (wind, human walking, or traffic). The main advantages of ambient vibration testing are: (1) testing is cheap and fast, as the equipment for excitation is unnecessary; (2) testing does not interfere with the operation of the structure; and (3) the measured response is representative of the real operating conditions of the structure. In this study, the ambient vibration tests are conducted on the Kömürhan Highway Bridge because of its many advantages.

The modal testing was applied on a lot of bridge types such as suspension bridges, cable-stayed bridges, highway bridges, historical masonry bridges, footbridges, high-speed railway bridges, and timber bridges. Ren et al. (2004) performed the free vibration tests to experimentally determine the dynamic characteristics of the Roebling Suspension Bridge. The bridge has a 321.9 main span over the Ohio River between Covington, Ky., and Cincinnati, Ohio. Ren et al. (2005) carried out an analytical and experimental modal analysis of the Qingzhou Cable-Stayed Bridge in Fuzhou, China. Its main span of $605 \mathrm{~m}$ is currently the longest span among the completed composite-deck cable-stayed bridges in the world. The field ambient vibration tests on the bridge deck and all stay cables were conducted just prior to the opening of the bridge. Vibration-based structural health monitoring of the Watson Wash and Vincent Thomas Highway Bridges was studied by Guan (2006). Bayraktar et al. (2007a) investigated the experimental dynamic characteristics of the Şinik Historical Masonry Bridge. The bridge has an arch type structural system. Bayraktar et al. (2007b) performed ambient vibration tests of an arch type steel footbridge with a main span of $35 \mathrm{~m}$ located in heavy traffic and a crowded area. The arch type steel footbridge deck consists of granite, aluminum, steel, sheet iron, and carrier beam. Xia et al. (2003) experimentally studied a high-speed railway bridge under Thalys trains. Peterson et al. (2003) carried out the application of dynamic system identification to timber bridges using laboratory models. However, there are not enough studies about the reinforced concrete prestresses box girder highway bridge. So, in this study, ambient vibration tests of the Kömürhan Highway Bridge constructed with the balanced cantilever method using reinforced concrete prestresses box girder are investigated to experimentally determine the dynamic characteristics. In addition, analytical dynamic characteristics are determined using SAP2000 software (Integrated Finite Element Analysis and Design of Structures, Computers and Structures, Inc., Berkeley, Calif.) and dynamic characteristics are compared with each other.

\section{Modal Parameter Extraction Technique: Peak Picking Method}

Ambient vibration tests are not appropriate for frequency response function or impulse response function calculations because the input excitations are not measured. The peak picking

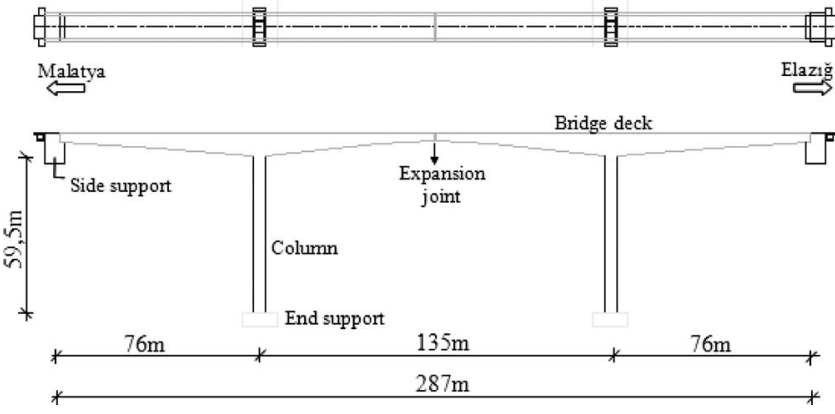

Fig. 2. Schematic representation of Kömürhan Bridge including plan and evaluation

(PP) method in the frequency domain is implemented here. The data processing and modal parameter identification are carried out using Operational Modal Analysis (OMA 2006). The PP method is primarily based on the fact that the frequency response function goes through an extreme around the natural frequencies. In the context of ambient vibration measurements, the frequency response function is replaced by the autospectra of the output-only data. To include the measurement channels of all setups, the average normalized power spectral densities (ANPSDs) are used. In this way, the identified natural frequencies are simply obtained from the observation of the peaks on the graphs of ANPSDs. The theoretical background and some application studies of the PP method can be obtained in the literature (Felber 1993; Bendat and Piersol 1986).

\section{Description of Kömürhan Highway Bridge}

The bridge deck consists of a main span of $135 \mathrm{~m}$ and two side spans of $76 \mathrm{~m}$ each. The total bridge length is $287 \mathrm{~m}$ and the width of the bridge is $11.50 \mathrm{~m}$. The following were used in the construction of the bridge: $1,340 \mathrm{t}$ building iron, $143 \mathrm{t}$ prestress steel, and $11,000 \mathrm{~m}^{3}$ concrete. The structural system of the Kömürhan Highway Bridge consists of a deck, columns, side support, and expansion joint. Schematic representation of the Kömürhan Bridge including plan and evaluation is given in Fig. 2.

\section{Bridge Deck}

The bridge's deck has a $287 \mathrm{~m}$ total span and $11.50 \mathrm{~m}$ width. The traffic on the bridge deck is traveling in two lanes (one going and the other turning). The deck of the bridge was constructed with a balanced cantilever and prestress box beam method. In the maintenance of current balance, segments constructed at the same time on the main columns in both directions come together and are added with prestress.

The deck consists of 56 segments. All of the segments are nearly $5 \mathrm{~m}$ in length. The height of the box girder is $9.35 \mathrm{~m}$ on the main columns, but it decreases parabolically $3.5 \mathrm{~m}$ at the side supports and $3.0 \mathrm{~m}$ at the expansion joint. The bottom thickness of the box girder increases parabolically from 0.23 to $0.65 \mathrm{~m}$ between side supports and main columns. Some dimensions of the box girder are given in Fig. 3 .

\section{Side Supports and Main Columns}

The side supports of the Kömürhan Highway Bridge are anchored by 60 unit $\oslash 36$ anchor rods at hard rock. The length of the 


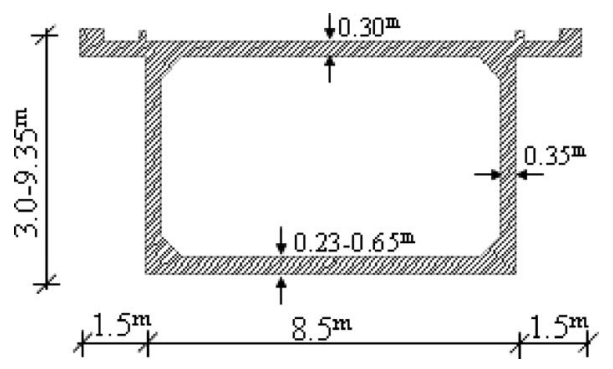

Fig. 3. Dimensions of box girder

anchor rod in the Elazı̆g and Malatya parts is 25 and $40 \mathrm{~m}$, respectively. Also, 80 unit tensile rods are used to anchor the deck at concrete wall of side supports. The length of these rods in Elazı $\breve{g}$ and Malatya parts are 4.7 and $3.7 \mathrm{~m}$, respectively.

There are two main columns of $59.50 \mathrm{~m}$ each. They consist of a variable section with three divisions. The width of the section deceases linearly from $14.40 \mathrm{~m}$ at the foundation to $8.50 \mathrm{~m}$ at the top of the column. To maintain the hydrostatic balance, transition of water at the column hulls and walls is permitted. Foundation of main column is concrete in mass having a dimension of $24 \times 13.5 \mathrm{~m}^{2}$ and $5 \mathrm{~m}$ depth. Variable column sections are given in Fig. 4.

\section{Expansion Joint}

To combine deck cantilevers, an expansion joint is constituted in the main span of the bridge. It consists of two IPB 600 steel beams. In this way, the edge of the cantilever at the main span is free and expansion with heat is allowed. Also, equivalent motion of the deck is provided under the vertical loads by developing a connection between two ends. Each of the beams is fixed by four pinned supports (two at the top and two at the bottom) in the Elazığ part and two roller supports (one at the top and one at the bottom) which has vertical load capacity in the Malatya part of the bridge. Therefore, the steel beam in the Elazı $\breve{g}$ part is fully fixed by blocking the rotation and motion freedom. Rotations and horizontal motions are allowed in the Malatya part; thus, a joint mechanism is formed. Also, transverse motion is prevented by side wedges. In Fig. 5, some view of the expansion joint can be seen.

\section{Ambient Vibration Test}

The responses of the Kömürhan Bridge are measured using B\&K 4506 type triaxial and B\&K 4507 type uniaxial accelerometers. The signals are acquired in the B\&K 3560 type data acquisition system and then transferred into the PULSE Lapshop software
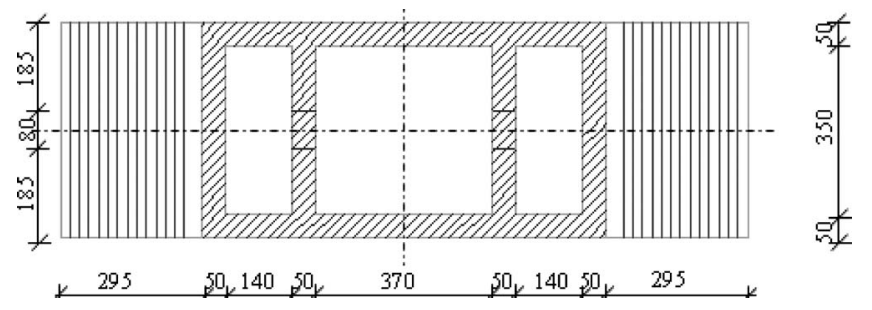

Fig. 4. View of variable section of the main columns $(\mathrm{cm})$

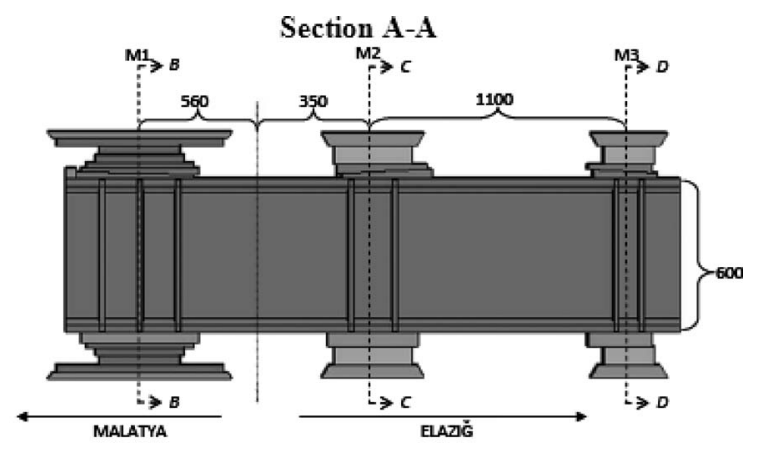

Perspective view

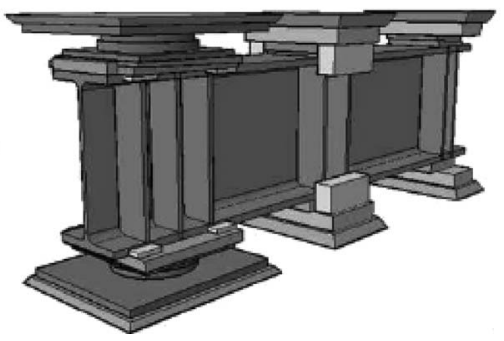

Fig. 5. Schematic view of the expansion joint mechanism (cm)

(PULSE 2006). For parameter estimation from the ambient vibration survey data, the Operational Modal Analysis software is used.

During the test in February 2008, normal traffic over the bridge was used as a source of ambient vibration. As input force was not measured, the use of Operational Modal Analysis to identify modal parameters was indispensable. Six ambient vibration modal tests were carried out during the period between February 25 and February 27, 2008. The first five setups are performed in the box girder and the other is conducted on the bridge deck. Due to the limited availability of sensors and data acquisition equipment, only nine sensor locations for each test setup could be monitored simultaneously. For each setup, four triaxial accelerometers in vertical, lateral, and longitudinal directions and one uniaxial accelerometer in vertical direction were used. Among these accelerometers, uniaxial was used as the reference accelerometer and its location unchanged throughout the test. The rest of the four accelerometers were used as roving accelerometers and were moved in order to cover all sensor locations.

\section{First Test Setup}

When the expansion joint mechanism in the middle of the bridge is considered, the Kömürhan Bridge can divide into two symmetrical parts as Elazığ and Malatya. So, it is thought that the

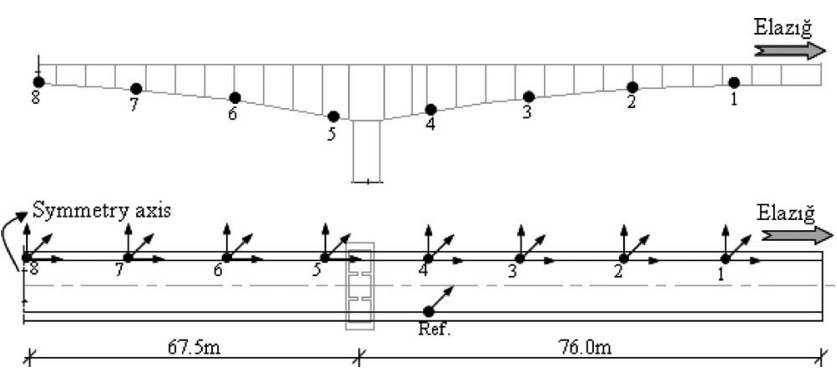

Fig. 6. Accelerometer location of the first setup on $2 \mathrm{D}$ views of the bridge 


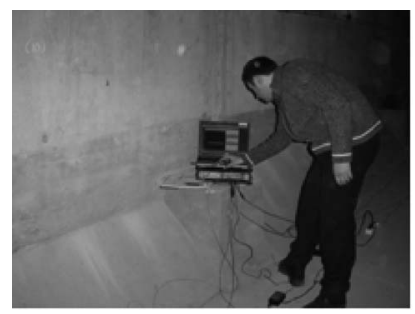

(a) Data logger

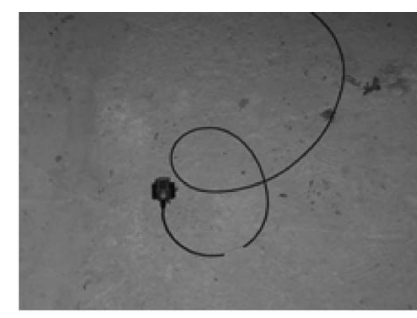

(b) Accelerometer
Fig. 7. Some views of experimental measurement system from the first setup: (a) data logger; (b) accelerometer

dynamic characteristics of these parts should be determined and compared with each other. Therefore the Elazı̆ is measured from the box girder along one way in the first setup.

Accelerometer locations of the first setup on the twodimensional (2D) views of the bridge models are given in Fig. 6. As the intended number of measurements is larger than the number of channels and sensors available, measurements are performed in two steps in the first test setup. In the first step, triaxial accelerometers are placed at Points 1-4 and in the second step

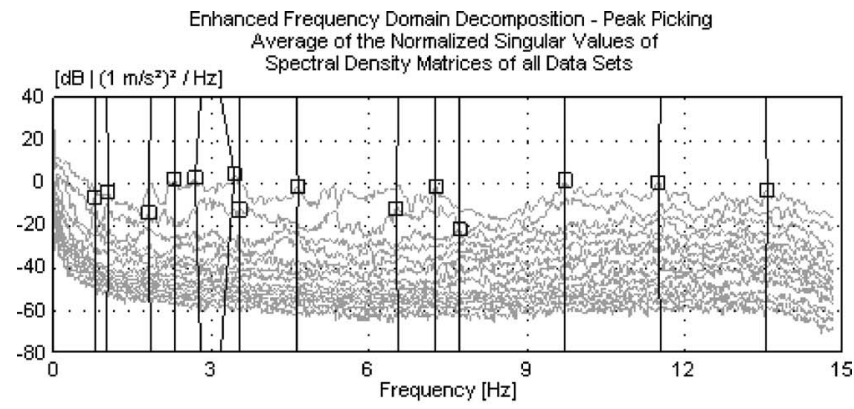

(a) Singular values of spectral density matrices

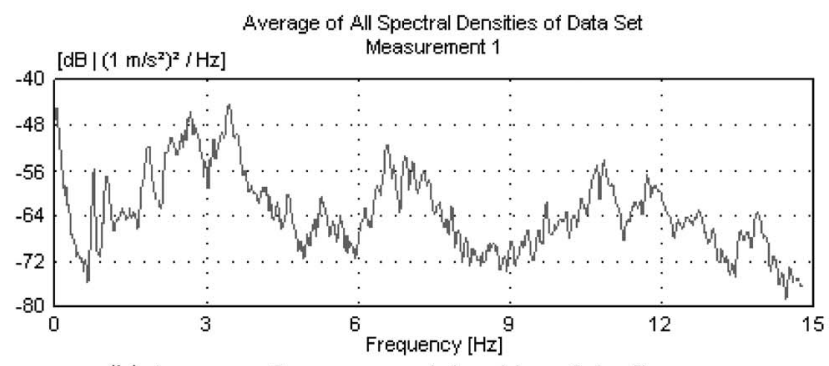

(b) A werage of auto spectral densities of the first step

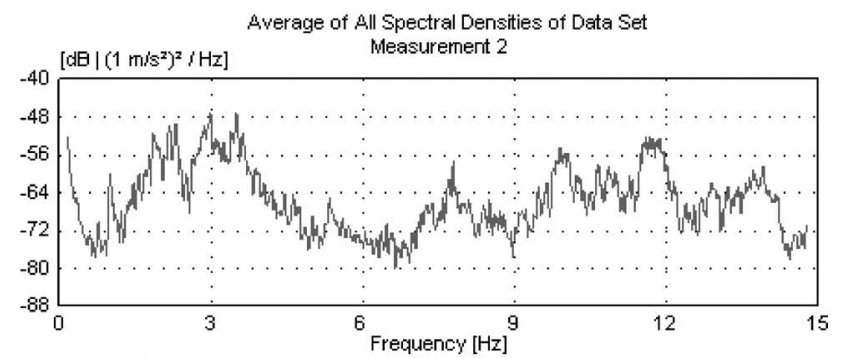

(c) Average of auto spectral densities of the second step

Fig. 8. Modal parameters attained from the first test setup using the peak peaking method: (a) singular values of spectral density matrices; (b) average of autospectral densities of the first step; and (c) average of autospectral densities of the second step
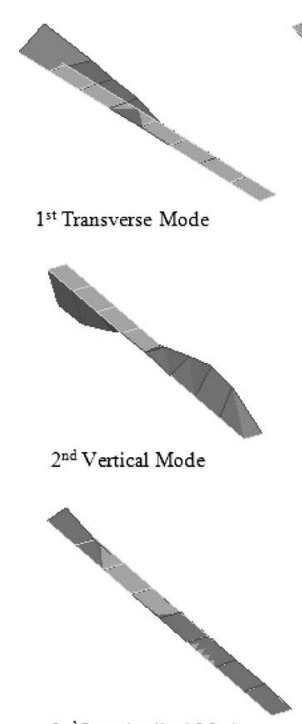

$3^{\text {rd }}$ Vertical Mode

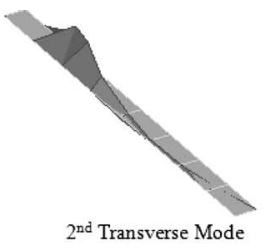

$2^{\text {nd }}$ Longitudinal Mode
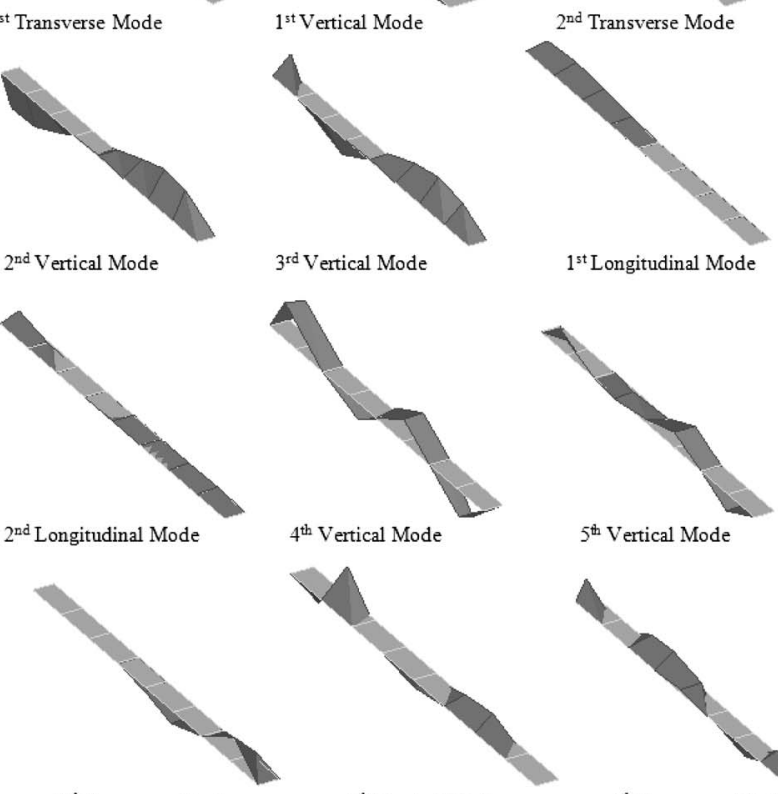

$1^{\text {st Longitudinal Mode }}$

$3^{\text {rd }}$ Transverse Mode
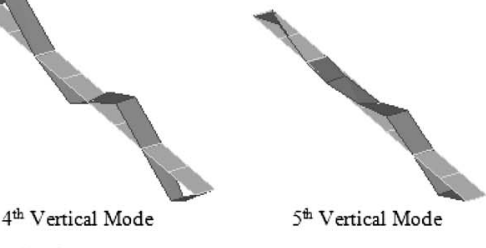

$5^{\text {th }}$ Vertical Mode

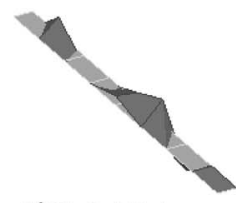

$7^{\text {th }}$ Vertical Mode

$8^{\text {th }}$ Vertical Mode

Fig. 9. Experimentally identified first 14 mode shapes

triaxial accelerometers are placed at Points 5-8 in Fig. 6. The signals in the first setup are incorporated using a reference uniaxial accelerometer. Some views of experimental equipment in the course of the first test setup are given in Fig. 7.

Singular values of spectral density matrices and autospectral densities of the first test setup attained from vibration signals using the PP method are shown in Fig. 8.

The first 14 mode shapes extracted from first setup are given in Fig. 9. Considering the first 14 mode shapes, these modes can be classified into three groups as vertical, transverse, and longitudinal modes.

\section{Second Test Setup}

In the second test setup, the Malatya part of the bridge is measured from the box girder along one way. Accelerometers are placed at the symmetry point of the first setup to compare the dynamic characteristics of the Elazığ and Malatya parts with each other.

Singular values of spectral density matrices and autospectral densities of the second test setup attained from vibration signals using the PP method are shown in Fig. 10.

The first 14 mode shapes extracted from the second setup are the same as the first setup. It can be seen from the first and second test results that there is a good agreement between the dynamic characteristics such as natural frequency, mode shapes, and damping ratios of the Elazığ and Malatya parts of the bridge. 


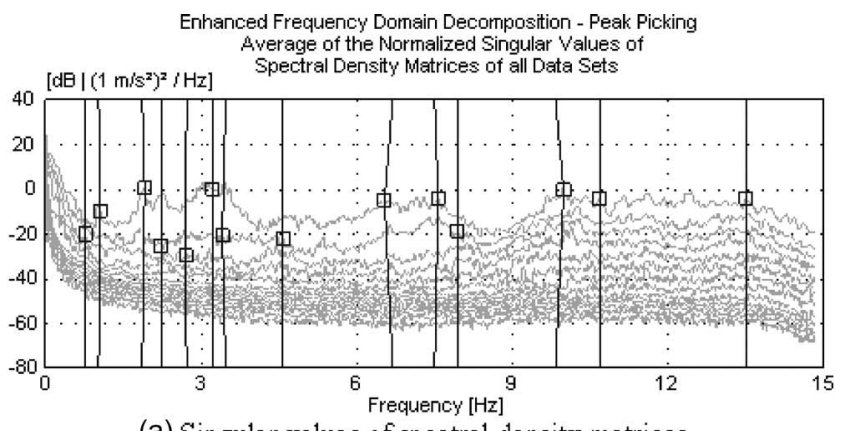

(a) Singular walues of spectral density matrices

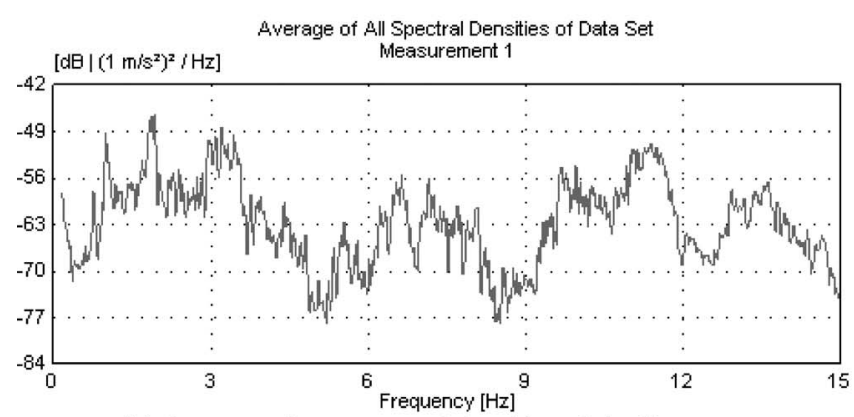

(b) Average of auto spectral densities of the first step

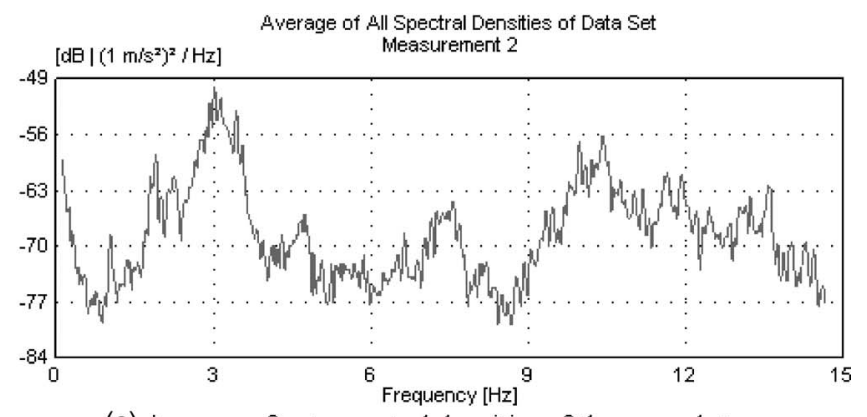

(c) Average of auto spectral densities of the second step

Fig. 10. Modal parameters attained from the second test setup using the peak peaking method: (a) singular values of spectral density matrices; (b) average of autospectral densities of the first step; and (c) average of autospectral densities of the second step

\section{Third Test Setup}

The Elazığ and Malatya parts of the bridge are measured and results are compared with each other. But, transverse effects are not determined because the first and second measurements are conducted in one direction. So, the third measurement is performed on reciprocal points in the box girder of the Elazı $\breve{g}$ part.

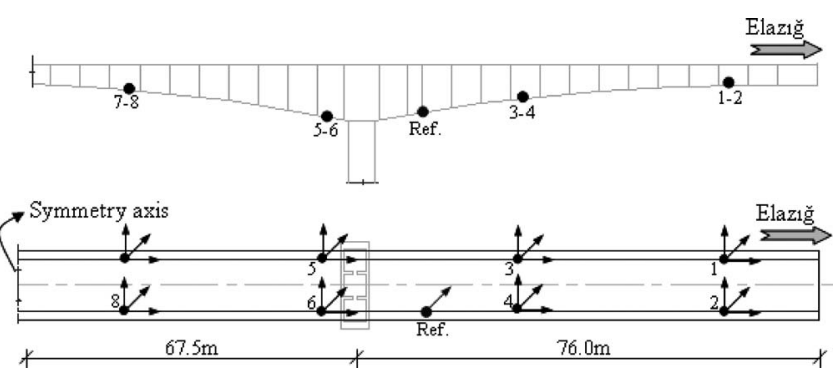

Fig. 11. Accelerometer locations of the third setup on $2 \mathrm{D}$ views of the bridge

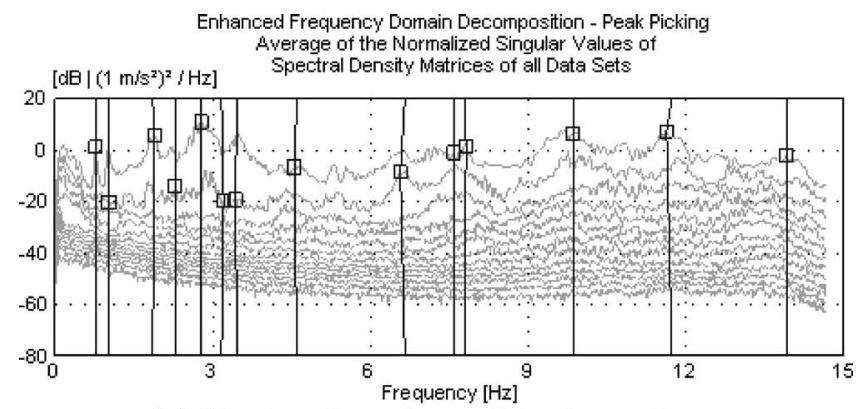

(a) Singular values of spectral density matrices

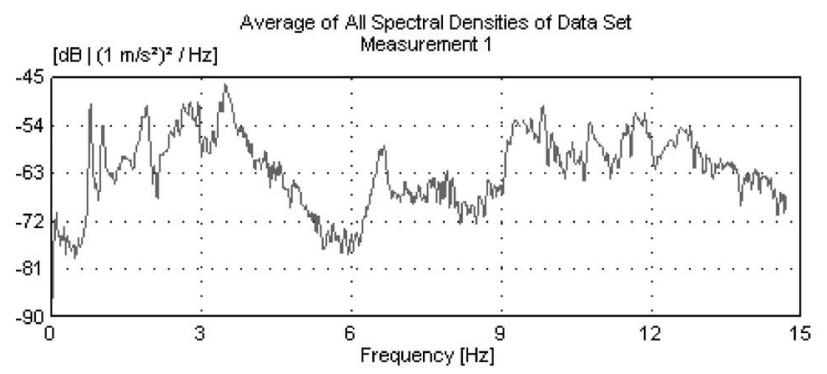

(b) Average of auto spectral densities of the first step

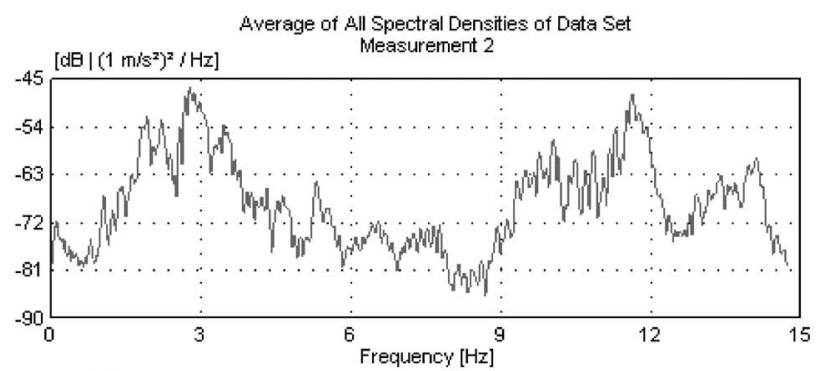

(c) Average of auto spectral densities of the second step

Fig. 12. Modal parameters attained from the third setup using the peak peaking method: (a) singular values of spectral density matrices; (b) average of autospectral densities of the first step; and (c) average of autospectral densities of the second step

Accelerometer locations of the third setup on the 2D views of the bridge models are given in Fig. 11. Measurements are performed in two steps in the third test setup. In the first step, triaxial accelerometers are placed at Points $1-4$ and in the second step triaxial accelerometers are placed at Points 5-8 in Fig. 11. The signals in the third setup are incorporated using a reference uniaxial accelerometer.

Singular values of spectral density matrices and autospectral densities of the third test setup attained from vibration signals using the PP method are shown in Fig. 12.

The first 14 mode shapes extracted from the third setup are same as the first two setups. The transverse modes become more pronounced by the third test setup.

\section{Fourth Test Setup}

In the fourth test setup, the Malatya part of the bridge is measured on reciprocal points in the box girder to obtain transverse effects more influentially. Accelerometers are placed at the symmetry point of the third setup to compare the dynamic characteristics of the Elazığ and Malatya parts. Singular values of spectral density 
Enhanced Frequency Domain Decomposition - Peak Picking Average of the Normalized Singular Values of $\left[\mathrm{dB} \mid\left(1 \mathrm{~m} / \mathrm{s}^{2}\right)^{2} / \mathrm{Hz}\right]$ Spectral Density Matrices of all Data Sets

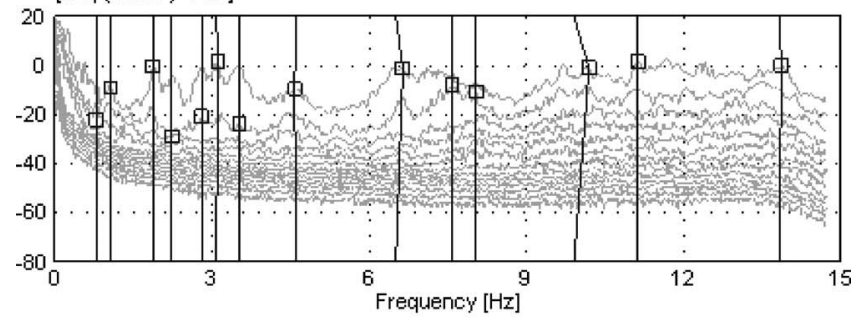

(a) Singular values of spectral density matrices

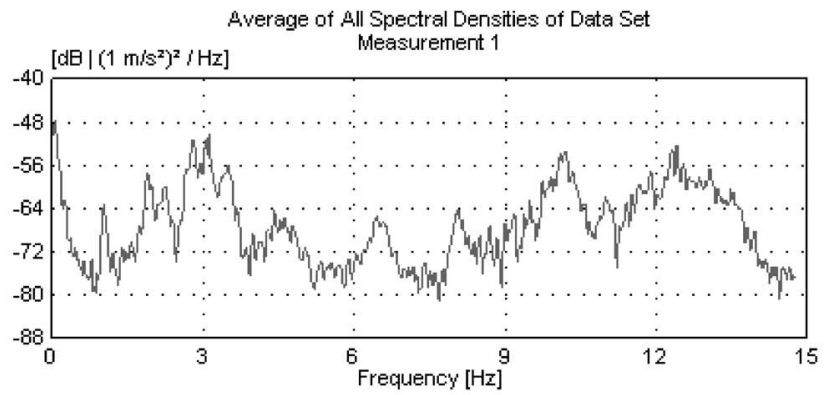

(b) Average of auto spectral densities of the first step

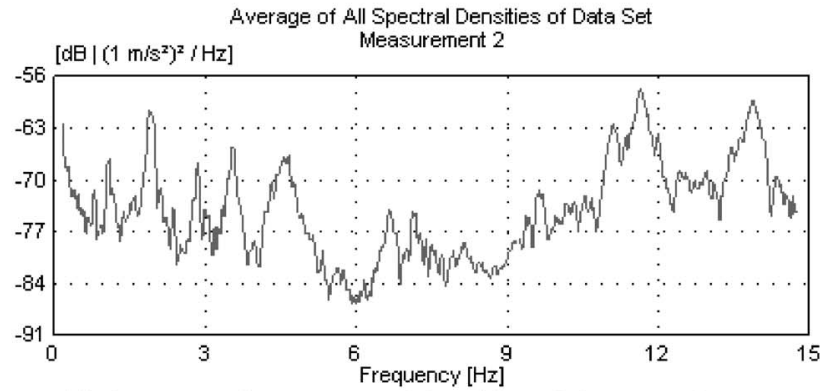

(c) Average of auto spectral densities of the second step

Fig. 13. Modal parameters attained from the fourth setup using the peak peaking method: (a) singular values of spectral density matrices; (b) average of autospectral densities of the first step; and (c) average of autospectral densities of the second step

matrices and autospectral densities of the fourth test setup attained from vibration signals using the PP method are shown in Fig. 13.

The first 14 mode shapes extracted from the fourth setup are the same as the first three setups. It can be seen from the first four test results that there is a good agreement between the dynamic
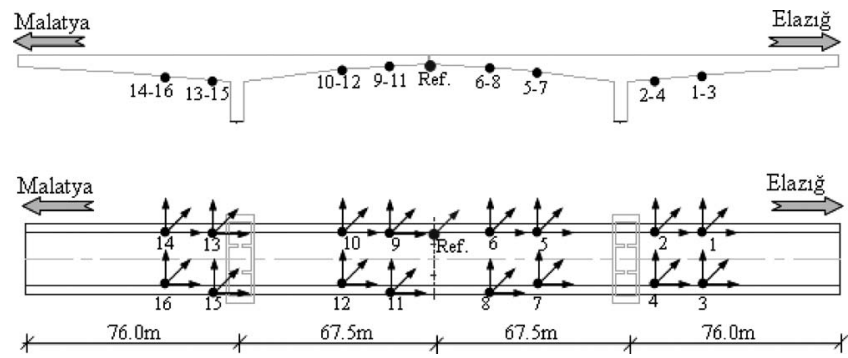

Fig. 14. Accelerometer locations of the fifth setup on $2 \mathrm{D}$ views of the bridge

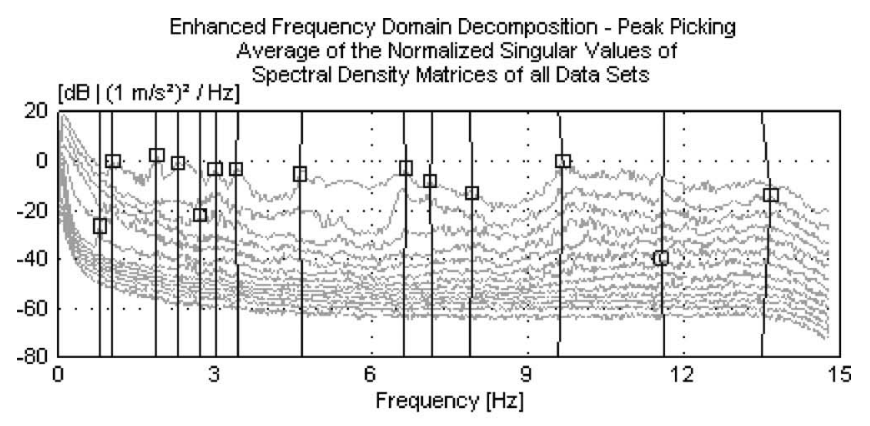

(a) Singular values of spectral density matrices

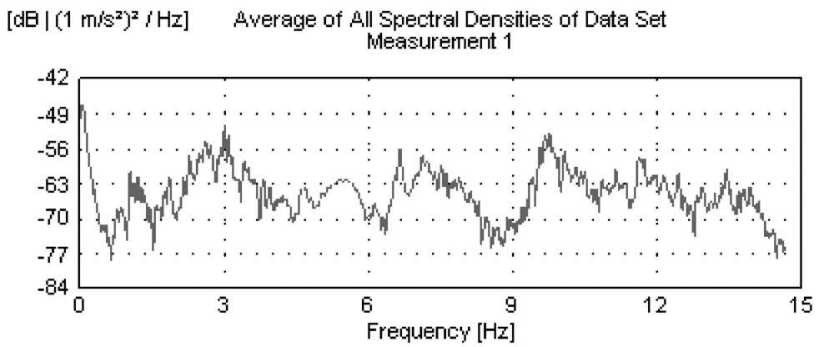

(b) Average of auto spectral densities of the first step

$\left[\mathrm{dB} \mid\left(1 \mathrm{~m} / \mathrm{s}^{2}\right)^{2} / \mathrm{Hz}\right] \quad$ Average of All Spectral Densities of Data Set

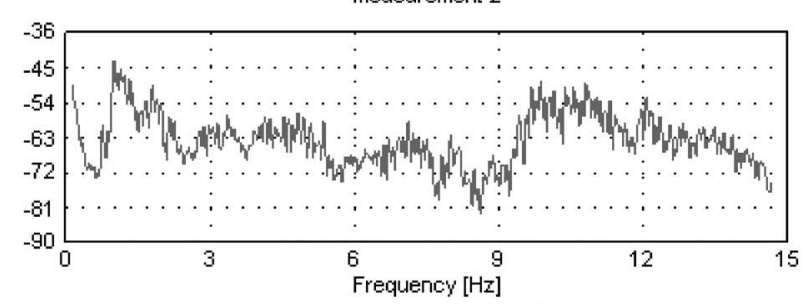

(c) Average of auto spectral densities of the second step

$\left[\mathrm{dE} \mid\left(1 \mathrm{~m} / \mathrm{s}^{2}\right)^{2} / \mathrm{Hz}\right] \quad$ Average of All Spectral Densities of Data Set

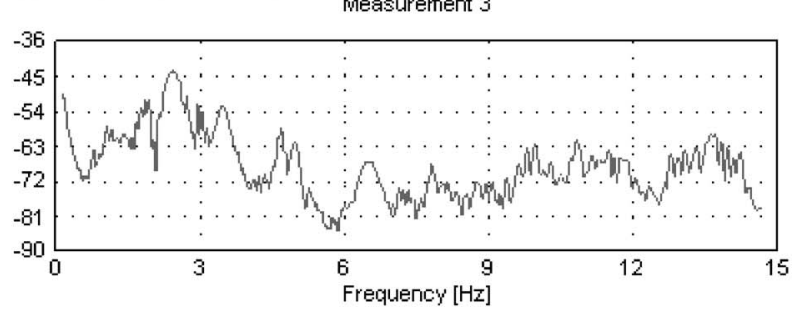

(d) Average of auto spectral densities of the third step

$\left[\mathrm{dB} \mid\left(1 \mathrm{~m} / \mathrm{s}^{2}\right)^{2} / \mathrm{Hz}\right] \quad$ Average of All Spectral Densities of Data Set

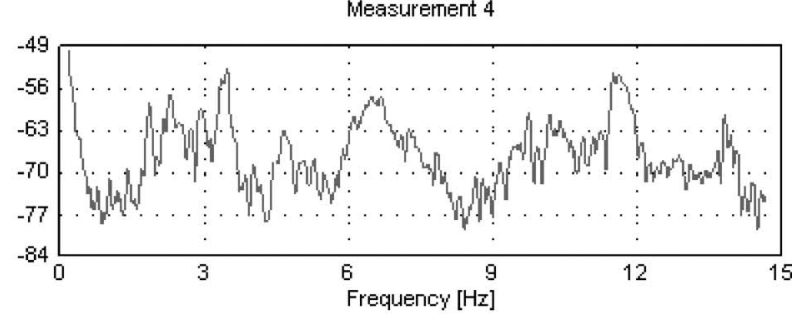

(e) Average of auto spectral densities of the fourth step

Fig. 15. Modal parameters attained from the fifth test setup using the peak picking method: (a) singular values of spectral density matrice; (b) average of autospectral densities of the first step; (c) average of autospectral densities of the second step; (d) average of autospectral densities of the third step; and (e) average of autospectral densities of the fourth step 


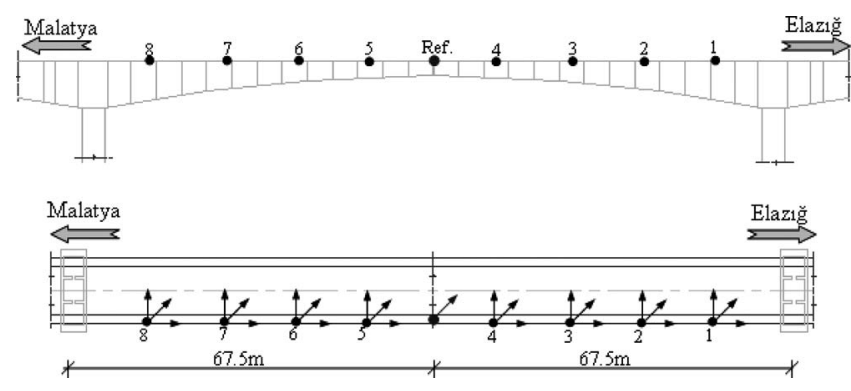

Fig. 16. Accelerometer locations of the sixth setup on $2 \mathrm{D}$ views of the bridge

characteristics of the Elazı $\breve{g}$ and Malatya parts of the bridge. Also, the transverse effects are determined more obviously from the third and fourth test setups.

\section{Fifth Test Setup}

The Elazı̆g and Malatya parts of the bridge are measured by different configurations and the results are compared with each other. But in the fifth measurement, the bridge is measured from end to end in the box girder.

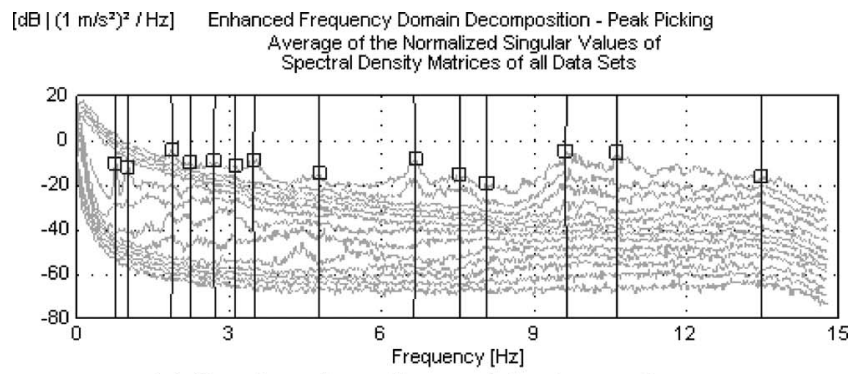

(a) Singular values of spectral density matrices

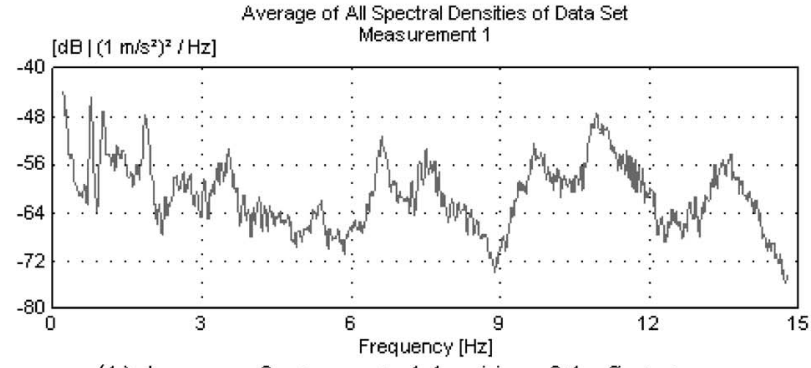

(b) Average of auto spectral densities of the first step

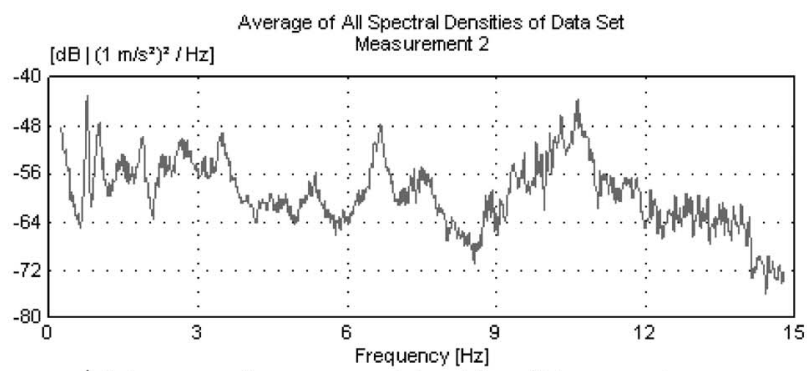

(c) Average of auto spectral densities of the second step

Fig. 17. Modal parameters attained from the sixth setup using the peak peaking method: (a) singular values of spectral density matrices; (b) average of autospectral densities of the first step; and (c) average of autospectral densities of the second step
Table 1. Experimental Modal Parameters Attained from the First Test Setup

\begin{tabular}{lcccc}
\hline & \multicolumn{3}{c}{ Average of autospectral densities } \\
\cline { 3 - 4 } Frequency & $\begin{array}{c}\text { Peak } \\
\text { picking } \\
\text { number }\end{array}$ & $\begin{array}{c}\text { First } \\
\text { step }\end{array}$ & $\begin{array}{c}\text { Second } \\
\text { step }\end{array}$ & $\begin{array}{c}\text { Damping } \\
\text { ratios }\end{array}$ \\
\hline 1 & 0.776 & 0.781 & 0.781 & 2.072 \\
2 & 1.014 & 1.020 & 1.000 & 3.554 \\
3 & 1.836 & 1.840 & 1.840 & 2.033 \\
4 & 2.310 & 2.300 & 2.310 & 2.065 \\
5 & 2.660 & 2.690 & 2.640 & 5.412 \\
6 & 3.178 & 3.140 & 3.000 & 1.912 \\
7 & 3.406 & 3.440 & 3.500 & 1.700 \\
8 & 4.623 & 4.610 & 4.630 & 2.145 \\
9 & 6.538 & 6.560 & 6.470 & 1.350 \\
10 & 7.272 & 7.600 & 7.700 & 0.950 \\
11 & 7.678 & 7.840 & 7.800 & 0.625 \\
12 & 9.709 & 9.720 & 9.890 & 0.223 \\
13 & 11.500 & 10.900 & 10.700 & 0.499 \\
14 & 13.560 & 13.900 & 13.900 & 0.168 \\
\hline
\end{tabular}

Accelerometer locations of the fifth setup on the 2D views of the bridge models are given in Fig. 14. Measurements are performed in four steps in the fifth test setup. In the first step, triaxial accelerometers are placed at Points $1-4$, in the second step triaxial accelerometers are placed at Points 5-8, in the third step triaxial accelerometers are placed at Points 9-12, and in the fourth step triaxial accelerometers are placed at Points 13-16 in Fig. 14. The signals in the fifth setup are incorporated using a reference uniaxial accelerometer located in the middle of the bridge.

Singular values of spectral density matrices and autospectral densities of the fifth test setup attained from vibration signals using the PP method are shown in Fig. 15. The first 14 mode shapes extracted from the fifth setup are the same as the first four setups.

Table 2. Experimental Modal Parameters Attained from the Second Test Setup

\begin{tabular}{lcccc}
\hline & \multicolumn{3}{c}{ Average of autospectral densities } \\
\cline { 3 - 4 } Frequency & $\begin{array}{c}\text { Peak } \\
\text { picking } \\
\text { number }\end{array}$ & $\begin{array}{c}\text { First } \\
\text { (Hz) }\end{array}$ & $\begin{array}{c}\text { Second } \\
\text { step }\end{array}$ & $\begin{array}{c}\text { Damping } \\
\text { ratios } \\
(\%)\end{array}$ \\
\hline 1 & 0.766 & 0.765 & 0.765 & 1.720 \\
2 & 1.020 & 1.000 & 1.030 & 3.211 \\
3 & 1.861 & 1.880 & 1.910 & 2.170 \\
4 & 2.230 & 2.280 & 2.230 & 0.707 \\
5 & 2.714 & 2.730 & 2.780 & 0.417 \\
6 & 3.211 & 3.200 & 3.020 & 1.937 \\
7 & 3.467 & 3.440 & 3.440 & 1.750 \\
8 & 4.575 & 4.400 & 4.730 & 1.826 \\
9 & 6.690 & 6.630 & 6.640 & 0.770 \\
10 & 7.494 & 7.140 & 7.550 & 0.962 \\
11 & 7.935 & 7.700 & 7.690 & 0.650 \\
12 & 9.825 & 9.690 & 9.970 & 0.400 \\
13 & 10.690 & 11.400 & 10.400 & 0.420 \\
14 & 13.500 & 13.600 & 13.600 & 0.130 \\
\hline
\end{tabular}


Table 3. Experimental Modal Parameters Attained from the Third Test Setup

\begin{tabular}{lcccc}
\hline & & \multicolumn{2}{c}{ Average of autospectral densities } \\
& Peak & \multicolumn{2}{c}{$(\mathrm{Hz})$} & \\
\cline { 3 - 4 } Frequency & $\begin{array}{c}\text { picking } \\
\text { number }\end{array}$ & $\begin{array}{c}\text { First } \\
\text { step }\end{array}$ & $\begin{array}{c}\text { Second } \\
\text { step }\end{array}$ & $\begin{array}{c}\text { ratios } \\
(\%)\end{array}$ \\
\hline 1 & 0.766 & 0.766 & 0.781 & 1.961 \\
2 & 1.016 & 1.020 & 1.050 & 3.411 \\
3 & 1.851 & 1.890 & 1.910 & 2.672 \\
4 & 2.290 & 2.370 & 2.200 & 1.329 \\
5 & 2.773 & 2.770 & 2.770 & 2.141 \\
6 & 3.162 & 3.220 & 3.270 & 1.070 \\
7 & 3.465 & 3.470 & 3.450 & 1.020 \\
8 & 4.595 & 4.550 & 4.630 & 2.300 \\
9 & 6.651 & 6.660 & 6.550 & 1.626 \\
10 & 7.571 & 7.340 & 7.250 & 0.875 \\
11 & 7.793 & 7.910 & 7.770 & 0.610 \\
12 & 9.872 & 9.830 & 10.01 & 0.550 \\
13 & 11.700 & 10.800 & 11.600 & 0.560 \\
14 & 13.910 & 13.600 & 13.400 & 0.240 \\
\hline
\end{tabular}

\section{Sixth Test Setup}

The fifth test setup is carried out in the box girder of the bridge. The sixth test setup is performed on the deck and only the main span between the two columns is measured along the one way.

Accelerometer locations of the sixth setup on the 2D views of the bridge models are given in Fig. 16. Measurements are performed in two steps in the sixth test setup. In the first step, triaxial accelerometers are placed at Points $1-4$ and in the second step triaxial accelerometers are placed at Points 5-8 in Fig. 16. The signals in the sixth setup are incorporated using a reference uniaxial accelerometer located in the middle of the bridge.

Singular values of spectral density matrices and autospectral densities of the sixth test setup attained from vibration signals using the PP method are shown in Fig. 17. Comparing all of the setups, there is good harmony between dynamic characteristics

Table 4. Experimental Modal Parameters Attained from the Fourth Test Setup

\begin{tabular}{lcccc}
\hline & & \multicolumn{2}{c}{ Average of autospectral densities } & \\
\cline { 3 - 4 } Frequency & $\begin{array}{c}\text { Peak } \\
\text { picking } \\
\text { number }\end{array}$ & $\begin{array}{c}\text { First } \\
(\mathrm{Hz})\end{array}$ & $\begin{array}{c}\text { Second } \\
\text { step }\end{array}$ & $\begin{array}{c}\text { Damping } \\
\text { ratios } \\
(\%)\end{array}$ \\
\hline 1 & 0.797 & 0.781 & 0.781 & 1.868 \\
2 & 1.049 & 1.020 & 1.060 & 2.993 \\
3 & 1.894 & 1.890 & 1.890 & 2.795 \\
4 & 2.234 & 2.250 & 2.360 & 0.706 \\
5 & 2.807 & 2.780 & 2.840 & 4.888 \\
6 & 3.090 & 3.110 & 3.020 & 1.750 \\
7 & 3.528 & 3.480 & 3.530 & 1.700 \\
8 & 4.586 & 4.410 & 4.560 & 1.707 \\
9 & 6.421 & 6.450 & 6.660 & 1.236 \\
10 & 7.587 & 7.410 & 7.110 & 0.835 \\
11 & 7.985 & 8.060 & 8.160 & 0.575 \\
12 & 9.907 & 10.20 & 9.620 & 0.203 \\
13 & 11.120 & 11.000 & 11.600 & 0.400 \\
14 & 13.820 & 13.450 & 13.900 & 0.170 \\
\hline
\end{tabular}

Table 5. Experimental Modal Parameters Attained from the Fifth Test Setup

\begin{tabular}{|c|c|c|c|c|c|c|}
\hline \multirow[b]{2}{*}{$\begin{array}{l}\text { Frequency } \\
\text { number }\end{array}$} & \multirow{2}{*}{$\begin{array}{c}\text { Peak } \\
\text { picking } \\
(\mathrm{Hz})\end{array}$} & \multicolumn{4}{|c|}{$\begin{array}{l}\text { Average of autospectral densities } \\
\qquad(\mathrm{Hz})\end{array}$} & \multirow{2}{*}{$\begin{array}{c}\text { Damping } \\
\text { ratios } \\
(\%)\end{array}$} \\
\hline & & $\begin{array}{l}\text { First } \\
\text { step }\end{array}$ & $\begin{array}{l}\text { Second } \\
\text { step }\end{array}$ & $\begin{array}{l}\text { Third } \\
\text { step }\end{array}$ & $\begin{array}{l}\text { Fourth } \\
\text { step }\end{array}$ & \\
\hline 1 & 0.788 & 0.781 & 0.765 & 0.796 & 0.781 & 1.373 \\
\hline 2 & 1.027 & 1.050 & 1.000 & 1.060 & 1.030 & 1.785 \\
\hline 3 & 1.850 & 1.860 & 1.800 & 1.900 & 1.860 & 2.057 \\
\hline 4 & 2.291 & 2.270 & 2.400 & 2.420 & 2.280 & 1.465 \\
\hline 5 & 2.703 & 2.610 & 2.750 & 2.720 & 2.730 & 1.420 \\
\hline 6 & 3.001 & 3.020 & 3.100 & 3.030 & 3.130 & 1.625 \\
\hline 7 & 3.440 & 3.420 & 3.360 & 3.450 & 3.470 & 2.400 \\
\hline 8 & 4.665 & 4.690 & 4.660 & 4.690 & 4.660 & 1.420 \\
\hline 9 & 6.612 & 6.660 & 6.660 & 6.550 & 6.480 & 1.167 \\
\hline 10 & 7.176 & 7.120 & 7.110 & 7.140 & 7.250 & 0.785 \\
\hline 11 & 7.896 & 7.500 & 8.000 & 7.800 & 7.840 & 0.590 \\
\hline 12 & 9.584 & 9.770 & 9.860 & 9.800 & 9.730 & 0.100 \\
\hline 13 & 11.620 & 11.600 & 10.820 & 10.800 & 11.500 & 0.300 \\
\hline 14 & 13.480 & 13.400 & 13.500 & 13.800 & 13.800 & 0.170 \\
\hline
\end{tabular}

and frequency span of the first fourteen modes. Natural frequencies and damping ratios obtained from six measurements are given in Tables 1-6.

\section{Finite-Element Analyses}

Finite-element model of the Kömürhan Bridge is constituted in the SAP2000 software considering the following design criteria:

- Bridge deck and columns are modeled using frame elements. The deck and columns consist of 56 and 10 segments, respectively. Section properties of each segment are assigned to frame elements.

- Posttension cables are modeled using frame elements constrained to rotation and fixed to the end of each segment. Posttension loads are considered as strain.

Table 6. Experimental Modal Parameters Attained from the Sixth Test Setup

\begin{tabular}{lcccc}
\hline & \multicolumn{3}{c}{ Average of autospectral densities } \\
\cline { 3 - 4 } Frequency & $\begin{array}{c}\text { Peak } \\
\text { picking } \\
\text { number }\end{array}$ & $\begin{array}{c}\text { First } \\
\text { (Hz) }\end{array}$ & $\begin{array}{c}\text { Second } \\
\text { step }\end{array}$ & $\begin{array}{c}\text { Damping } \\
\text { ratios } \\
(\%)\end{array}$ \\
\hline 1 & 0.764 & 0.766 & 0.766 & 3.263 \\
2 & 1.010 & 1.020 & 1.020 & 2.140 \\
3 & 1.862 & 1.860 & 1.870 & 1.409 \\
4 & 2.219 & 2.270 & 2.300 & 1.314 \\
5 & 2.710 & 2.630 & 2.690 & 0.578 \\
6 & 3.118 & 3.050 & 3.120 & 1.250 \\
7 & 3.491 & 3.530 & 3.480 & 2.400 \\
8 & 4.754 & 4.440 & 4.450 & 1.400 \\
9 & 6.636 & 6.610 & 6.670 & 1.370 \\
10 & 7.528 & 7.520 & 7.470 & 0.810 \\
11 & 8.079 & 8.020 & 8.090 & 0.700 \\
12 & 9.648 & 9.670 & 9.56 & 0.370 \\
13 & 10.630 & 10.900 & 10.600 & 0.460 \\
14 & 13.480 & 13.600 & 13.500 & 0.120 \\
\hline
\end{tabular}


Table 7. Material Properties Used in the Analytical Model

\begin{tabular}{lccc}
\hline Materials & $\begin{array}{c}\text { Elasticity } \\
\text { modulus } \\
\left(\mathrm{N} / \mathrm{m}^{2}\right)\end{array}$ & $\begin{array}{c}\text { Poisson } \\
\text { ratios }\end{array}$ & $\begin{array}{c}\text { Mass per unit } \\
\text { volume } \\
\left(\mathrm{kg} / \mathrm{m}^{3}\right)\end{array}$ \\
\hline Deck & $4.25 \mathrm{E} 10$ & 0.2 & 2,500 \\
Columns & $4.25 \mathrm{E} 10$ & 0.2 & 2,500 \\
Prestress elements & $1.95 \mathrm{E} 11$ & 0 & 0 \\
Rigidity elements & $1.0 \mathrm{E} 15$ & 0.3 & 0 \\
\hline
\end{tabular}

- Boundary conditions of the ends of the deck are defined using very rigid springs.

- The expansion joint in the middle of the bridge is modeled by spring element to allow movement in the longitudinal directions.

Material properties used in the analyses are given in Table 7. 2D and three-dimensional finite-element models of the Kömürhan Bridge are given in Fig. 18. The first 14 mode shapes obtained from the analytical analyses of the Kömürhan Bridge are given in Fig. 19. When the dynamic characteristics are obtained from finite-element analyses and experimental measurement, good harmony found.

\section{Conclusions}

In this paper, dynamic characteristics of the Kömürhan Bridge located on the Elazı $\breve{g}$-Malatya Highway in Turkey are determined using ambient vibration tests. There are six different test setups in the box girder and on the deck are performed under natural excitations such as traffic loads. Comparing the result of the study, the following observations can be made.

From the ambient vibration tests of the bridge a total of 14 natural frequencies are attained experimentally, which range between 0 and $14 \mathrm{~Hz}$. Considering the first 14 mode shapes, these modes can be classified into vertical, transverse, and longitudinal modes.

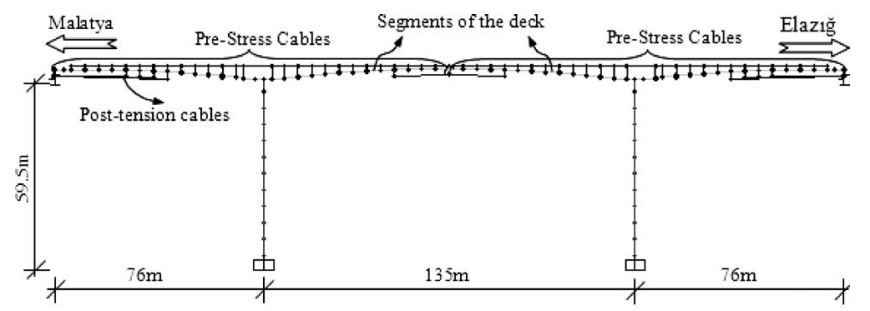

(a) 2D finite element model

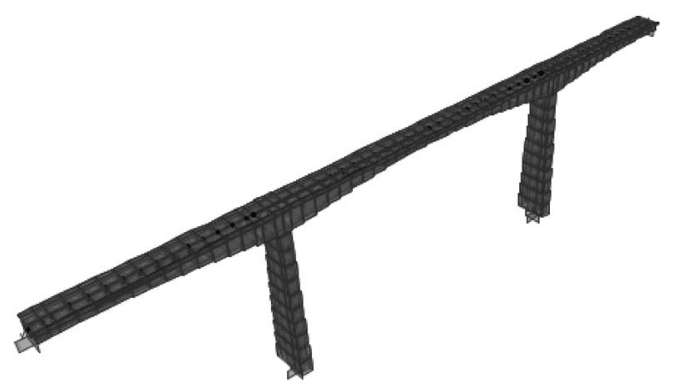

(b) 3D finite element model

Fig. 18. 2D and 3D finite-element models of the Kömürhan Bridge: (a) 2D finite-element model; (b) 3D finite-element model
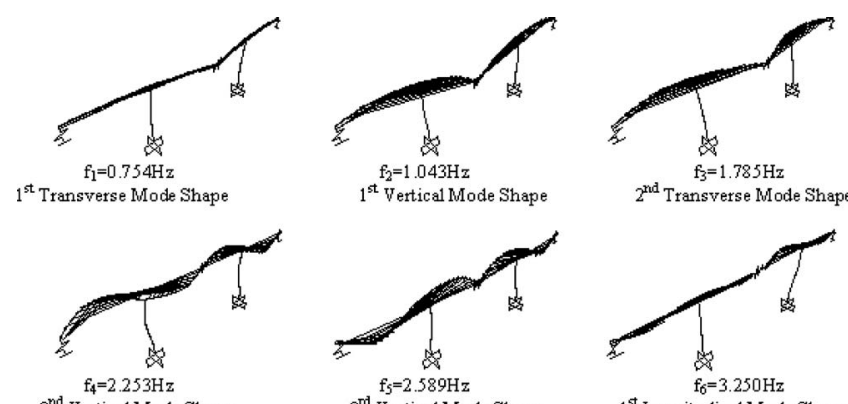

$2^{\text {nd }}$ Vertical Mode Shape
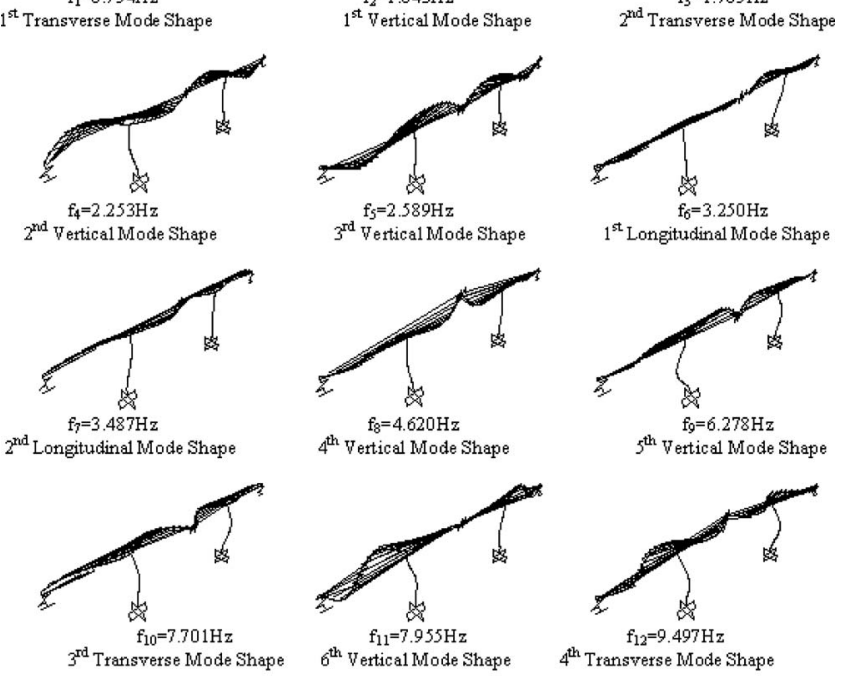

$\mathrm{f}_{6}=3.250 \mathrm{~Hz}$ $1^{\text {st }}$ Longitudinal Mode Shape
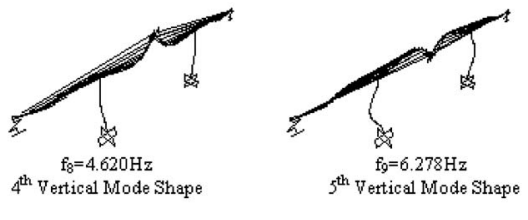

$\mathrm{f}_{\mathrm{g}}=6.278 \mathrm{~Hz}$ $5^{\text {th }}$ Vertical Mode Shape
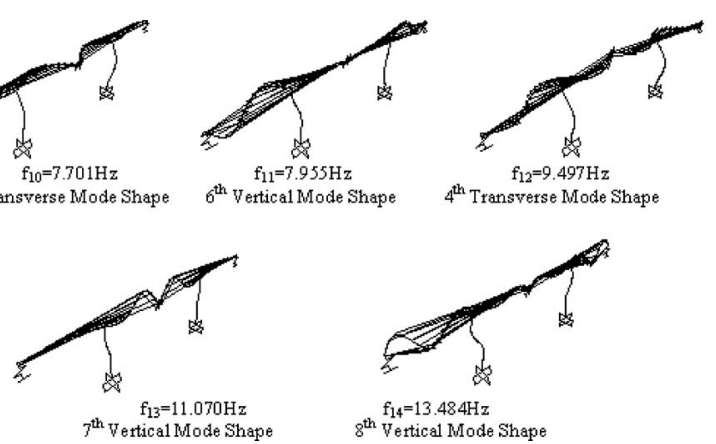

Fig. 19. Analytically identified first 14 mode shapes

The ambient vibration testing is conducted under the environmental excitations in the box girder and on the bridge deck to accurately extract the dynamic characteristics using the PP method. The bridge can be divided into two symmetrical parts; Elazı $\breve{g}$ and Malatya, with expansion joint mechanism. When the first two test setup (also the third and fourth setup) results are examined, good agreement is seen among the dynamic characteristics such as natural frequency, mode shapes, and damping ratios of the Elazığ and Malatya parts of the bridge. Also, transverse modes are determined more obviously from the experimental test setups where the accelerometers are located at the reciprocal points.

From the modal analysis of the finite-element model of the bridge, a total of 14 natural frequencies are attained analytically, which range between 0 and $14 \mathrm{~Hz}$. Considering the first seven mode shapes, these modes can be classified into vertical, transverse, and longitudinal modes.

When comparing the finite element and experimental results, it is seen that there is good harmony but little difference between results. It is thought that these differences resulted from some uncertainties in the structural geometry, material properties, and boundary conditions accepted in the design phase of the bridge. So, the finite-element model of the bridge must be updated by using uncertain parameters to eliminate the differences in the next studies.

\section{Acknowledgments}

This research was supported by the TUBITAK and Karadeniz Technical University under Research Grant Nos. 106M038, 2005.112.001.1, and 2006.112.001.1, respectively. Many thanks 
to Mehmet Fidan and Yavuzhan Taş, engineers at the 8th General Directorate of Highways, and K. Arman Domaniç, engineer at the Yüksel Domaniç Engineering Company, for supplying the logistical support.

\section{References}

Bayraktar, A., Altunışık, A. C., Sevim, B., and Türker, T. (2007a). "Modal testing and finite element model updating of an arch type steel footbridge." Steel Compos. Struct., 7(6), 487-502.

Bayraktar, A., Altunışık, A. C., Türker, T., and Sevim, B. (2007b). "The model updating of historical masonry bridges using operational modal analysis method." Symp., 1st Reinforcement and Transfer into the Future of Historical Structures, Ankara, Turkey, 429-440.

Bendat, J. S., and Piersol, A. G. (1986). Random data: Analysis and measurement procedures, Wiley, New York.

Felber, A. J. (1993). "Development of hybrid bridge evaluation system."
Ph.D. thesis, Univ. of British Columbia, Vancouver, B.C., Canada.

Guan, H. (2006). "Vibration-based structural health monitoring of highway bridges." Ph.D. thesis, Univ. of California, San Diego.

OMA. (2006). "Operational modal analysis, release 4.0." Structural Vibration Solution A/S, Denmark.

Peterson, S. T., Mclean, D. I., and Pollock, D. G. (2003). "Application of dynamic system identification to timber brides." J. Struct. Eng., 129(1), 116-124.

PULSE. (2006). "Labshop, Version 11.2.2." Brüel \& Kjaer Sound and Vibration Measurement A/S.

Ren, W. X., Blanford, G. E., and Harik, I. E. (2004). "Roebling suspension bridge. I: Finite-element model and free vibration response." J. Bridge Eng., 9(2), 110-118.

Ren, W. X., Peng, X. L., and Lin, Y. Q. (2005). "Experimental and analytical studies on dynamic characteristics of a large span cable-stayed bridge." Eng. Struct., 27(4), 535-548.

Xia, H., De Roeck, G., Zhang, N., and Maeck, J. (2003). "Experimental analysis of a high-speed railway bridge under Thalys trains." J. Sound Vib., 268(1), 103-113. 